\title{
Construção Social nas Redes: ${ }^{1}$
}

\section{conflitos em comentários no Facebook da Folha de São Paulo e Estadão}

\section{Social Construction on the Web:}

\section{conflicts on Facebook's pages of Folha de São Paulo and Estadão}

\section{Manuel Luís Petrik} Jornalista e Doutor em Comunicação Social pela Pontifícia Universidade Católica do Rio Grande do Sul. PUC-RS, Departamento de Comunicação Social, Porto Alegre (RS), Brasil.

\section{Introdução}

Jean Baudrillard (1990) criou, com ironia, uma metáfora que serve não só para o entendimento de uma época, como também de ilustração à interpretação intelectual que a acompanhava: a imagem que resumiria o século XX era a de um trabalhador em casa, em um dia de greve, diante de uma televisão fora do ar. No século XXI, a submissão consentida dá lugar à ação, o receptor volta a ser sujeito, e uma das imagens do tempo atual, menos metafórica e mais referenciada, é a do indivíduo deblaterando nas redes sociais, em casa, no trabalho ou na esquina, enquanto aguarda para atravessar a rua, sobre qualquer assunto. Investigar quais são esses assuntos e a forma como se articulam nas mensagens dos novos receptores-emissores é o desafio pretendido neste trabalho.

\footnotetext{
${ }^{1}$ Uma versão preliminar deste trabalho foi apresentada na DT 7 - Comunicação, Espaço e Cidadania do XX Congresso de Ciências da Comunicação na Região Sul - Intercom-Sul, realizado de 20 a 22 de junho de 2019, em Porto Alegre.
} 
A emergência das mídias sociais vem despertando o interesse acadêmico, especialmente na área das Ciências Sociais Aplicadas. Violência simbólica e ódio têm sido os aspectos bastante contemplados em tais abordagens. O conflito em si, predecessor a essas duas instâncias extremadas, não figura como objeto preponderante nas análises, sendo que a atenção ao polemismo em torno de temas cruciais para os desígnios do país é menos comum na área. Inúmeras podem ser as causas para tal omissão. Sob o ponto de vista acadêmico e pela passionalidade envolvida, a versão mais cruenta dos embates, que aflui para a raiva e sentimentos radicais, torna-se um alvo mais próximo e tangível para a preocupação de pesquisadores.

A polêmica em si como objeto próprio de interesse teórico também é rara. Experiências intersubjetivas, as polêmicas podem ser entendidas como uma face da realidade cotidiana, e, assim, a sociologia de base fenomenológica de Alfred Schütz oferece-se como uma viável alternativa. Defendia o autor austríaco que "O mundo da vida cotidiana é a região em que cada indivíduo pode engajar a si mesmo e que o pode mudar enquanto opera nele pelos meios de seu organismo animado" (SCHÜTZ, LUCKMANN, 1973, p.3, tradução minha²). Para além do corpo físico, tal definição pode agora ser estendida ao entendimento das manifestações e ações do homem em suporte virtual em rede. ${ }^{3}$ Nesse sentido, buscaremos compreender as necessidades do homem em realizar projetos, do nível cotidiano ao abstrato, e os conflitos daí decorrentes. Intenta-se evidenciar aquela proposição de Georg Simmel segundo a qual o conflito "está destinado a resolver dualismo divergente; é um modo de conseguir unidade (SIMMEL, 1983, p. 122)". Partindo disso, o objetivo do presente trabalho é identificar quais temáticas levantam mais polêmicas e elaborar uma tipologia de comentários, por intermédio da análise de duas semanas de postagens nas páginas da Folha de São Paulo e de O Estado de São Paulo no Facebook. A partir dessas duas instâncias, busca-se uma reflexão mais ampla sobre o fenômeno atual dos comentários on-line.

\section{Análise de dados: polêmica e conflito}

Para este trabalho não há eleição de um assunto tema como sendo preponderante, seguindo a orientação metodológica da Teoria Fundamentada -TF (GLASER, STRAUSS, 2006). Trata-se de uma concepção

\footnotetext{
2 "The everyday life-world is the region of reality in wich man can engage himself and wich he can change while he operates in it by means of his animate organism".

${ }^{3}$ Alexander Halavais (2015) observa que "O cientista social de hoje se encontra diante de uma oportunidade magnífica. A internet coloca o mundo social, em todo seu desarranjo e complexidade, na soleira da sua porta. Os métodos empíricos e as teorias empíricas da metade do século XX parecem inadequados para desatar esse nó górdio." Eis que, ao contrário do que diz, uma teoria concebida justamente em meados do século passado se faz novamente atual.
} 
no sentido inverso ao normalmente adotado nas Ciências Sociais, em corroborar as teorias já existentes com a coleta de dados. Na TF, os dados fazem emergir a teoria, como forma de produzir uma teorização adequada para entendimento de determinados fenômenos, a fim de se evitar a prevalência da verificação a partir de uma "teoria gerada por dedução lógica derivada de suposições a priori"4 (GLASER, STRAUSS, 2006, p. 3, tradução minha). Trata-se de um procedimento de cunho exploratório em que a análise dos dados se conjuga com a discussão teórica.

Há que se destacar a aplicabilidade da Teoria Fundamentada, aberta por princípio, a um campo ainda novo como é o caso dos fenômenos sociais associados e desenrolados em ambientes com suporte virtual. Quando se fala em excesso, como é o caso dos comentários, deve-se, na medida do possível, partir de uma incursão livre de prenoções, em que os dados emerjam mais pelo que são do que por subordinação teórica ou compromisso ideológico, em um processo de afastar-se para a aproximação. Como defendem Fragoso, Recuero e Amaral (2015, p. 87), a TF é "particularmente interessante aos dados obtidos em um campo onde ainda há uma profusão de dados e ainda um pequeno corpo teórico, como é o caso dos fenômenos do ciberespaço". A proposição das autoras é ainda mais válida se observarmos que a relação geração de dados $x$ produção de teoria ainda é desigual, principalmente face à velocidade do surgimento de novas tecnologias conectivas e ao aumento do engajamento dos indivíduos com estas, fazendo aparecer, a todo instante, novas interações sociais e recriações.

Sob o ponto de vista de ordenação textual, a Teoria Fundamentada reordena a apresentação usual, já que o referencial teórico só é selecionado e discutido após a exposição dos dados. Para a compreensão desses, segue-se, aqui, o modelo de codificação em três níveis: aberta, axial e seletiva (ROSENTHAL, 2014; FRAGOSO, RECUERO e AMARAL, 2015). A primeira constitui-se a partir da análise preliminar dos dados emergentes; são as descobertas mais evidentes após a coleta inicial. Na segunda, refinam-se essas noções preliminares, criando-se novas subcategorias a partir de uma análise mais detalhada. Ao cruzamento entre as primeiras categorias e essas segundas deu-se o nome de codificação seletiva, a terceira etapa do processo. Cabe ressaltar que neste trabalho a orientação teórica segue, em parte, a metodológica, já que, como observa Charmaz (2009), entre as possíveis variantes da Teoria Fundamentada está a construcionista, cuja lógica de abordagem "refere-se a descobrir como, quando e até que ponto a experiência estudada está

\footnotetext{
4 "Theory generated by logical deduction from a priori assumptions".
} 
inserida em posturas, redes, situações e relações mais amplas e, muitas vezes, ocultas" (CHARMAZ, 2009, p. 179).

A atenção recai sobre a polêmica como dinâmica comunicacional e, a partir daí, sobre os temas pelos quais os atores se mobilizam, como se estruturam, e a provável repercussão social do fenômeno. Buscou-se verificar os temas que mobilizavam maior número de comentários nas postagens das páginas da Folha de São Paulo e de O Estado de São Paulo no Facebook ${ }^{5}$. A primeira, entre os grandes jornais brasileiros, contava com maior número de seguidores, próximo aos 6 milhões, tendo o Estadão cerca de 3,7 milhões. A coleta contemplou o período de duas semanas de publicações (entre os dias 4 e 10 de outubro de 2017, no caso da Folha, e entre 20 e 26 de agosto de 2018, na página do Estado). Ao longo dessa semana, sempre 14 horas depois da última postagem do dia anterior, eram recolhidos todos os posts na página do jornal na referida rede, com título, número de comentários e hiperlink de cada um.

Durante a coleta, foram elaboradas categorias temáticas para as postagens (Comportamento / Moral; Política / Nacional; Entretenimento / Showbiz; Serviços / Utilidades; Economia / Finanças pessoais; Mundo / Relações internacionais), originadas a partir das tradicionais editorias jornalísticas (economia, política, variedades, etc), Tais categorias emergiram do contato inicial do autor com a coleta, em processo correspondente à etapa de codificação aberta da Teoria Fundamentada, e foram nomeadas a partir da percepção de que as seções dos jornais não contemplavam da melhor forma os assuntos predominantes dos textos noticiosos. Em seguida, analisam-se os principais comentários da publicação com maior número de manifestações de usuários por dia.

É na análise dos comentários que se parte, então, para a fase da codificação axial da TF, na qual se procurou criar uma tipologia dos comentários. Trata-se de uma segunda etapa, pois os comentários estavam,

\footnotetext{
5 Disponível em: https://www.facebook.com/folhadesp/. Acesso em: 30 nov. 2018; Disponível em: https://www.facebook.com/estadao/. Acesso em: 7 dez. 2018. Em 11 de janeiro de 2018, o próprio Mark Zuckerberg, fundador e presidente do Facebook, veio anunciar que a empresa reduziria o espaço dos conteúdos jornalísticos, a fim de privilegiar posts pessoais, buscando "ajudar os usuários a encontrar conteúdo relevante e criar interações sociais mais significativas" (Disponível em: $\quad$ https://link.estadao.com.br/noticias/empresas,facebook-vai-privilegiar-posts-de-amigos-e-conteudo-jornalistico-teramenos-espaco,70002148250. Acesso em: 30 jun. 2018). Em 8 de fevereiro de 2018, a Folha de São Paulo comunicou a decisão de não mais atualizar a página que mantinha naquela rede social como "reflexo de discussões internas sobre os melhores caminhos para fazer com que o conteúdo do jornal chegue a seus leitores". A página segue na rede, ainda recebendo comentários de usuários com certa frequência, mesmo tendo a última postagem jornalística com data de 8 de fevereiro (Disponível em: https://www1.folha.uol.com.br/poder/2018/02/folha-deixa-de-publicar-conteudo-no-facebook.shtml. Acesso em: 30 jun. 2018).
} 
sempre, em relação com as postagens dos jornais, constituindo o segundo momento de pesquisa. Logo após, cruzam-se as duas instâncias em uma reflexão mais profunda, correspondendo a uma codificação seletiva.

Tabela 1: Posts da Folha mais comentados por dia, por categoria

\begin{tabular}{|c|c|c|c|c|c|c|c|}
\hline Dia & $\begin{array}{l}\text { 4/10/17 } \\
\text { 4a feira }\end{array}$ & $\begin{array}{l}5 / 10 / 17 \\
5 \text { a feira }\end{array}$ & $\begin{array}{l}\text { 6/10/17 } \\
\text { 6a feira }\end{array}$ & $\begin{array}{l}\text { 7/10/17 } \\
\text { Sábado }\end{array}$ & $\begin{array}{l}8 / 10 / 17 \\
\text { Domingo }\end{array}$ & $\begin{array}{l}9 / 10 / 17 \\
2 \text { afeira }\end{array}$ & $\begin{array}{l}\text { 10/10/17 } \\
\text { 3a feira }\end{array}$ \\
\hline $\begin{array}{l}\text { Categoria } \\
\text { post mais } \\
\text { comenta. }\end{array}$ & $\begin{array}{l}\text { Comporta- } \\
\text { mento/ } \\
\text { Moral }^{6}\end{array}$ & $\begin{array}{l}\text { Comporta- } \\
\text { mento/ } \\
\text { Moral }^{7}\end{array}$ & $\begin{array}{l}\text { Entreteni- } \\
\text { mento/ } \\
\text { Showbiz }^{8}\end{array}$ & $\begin{array}{l}\text { Entreteni- } \\
\text { mento/ } \\
\text { Showbiz }^{9}\end{array}$ & $\begin{array}{l}\text { Comporta- } \\
\text { mento/ } \\
\text { Moral }^{10}\end{array}$ & $\begin{array}{l}\text { Política/ } \\
\text { Nacional }^{11}\end{array}$ & $\begin{array}{l}\text { Política/ } \\
\text { Nacional }^{12}\end{array}$ \\
\hline $\begin{array}{l}\text { Categoria } \\
\text { segundo } \\
\text { post mais } \\
\text { comenta. }\end{array}$ & $\begin{array}{l}\text { Política/ } \\
\text { Nacional }^{13}\end{array}$ & $\begin{array}{l}\text { Política/ } \\
\text { Nacional }^{14}\end{array}$ & $\begin{array}{l}\text { Política/ } \\
\text { Nacional }^{15}\end{array}$ & $\begin{array}{l}\text { Comporta- } \\
\text { mento/ } \\
\text { Moral }^{16}\end{array}$ & $\begin{array}{l}\text { Comporta- } \\
\text { mento/ } \\
\text { Moral }^{17}\end{array}$ & $\begin{array}{l}\text { Comporta- } \\
\text { mento/ } \\
\text { Moral }^{18}\end{array}$ & $\begin{array}{l}\text { Comporta- } \\
\text { mento/ } \\
\text { Moral }^{19}\end{array}$ \\
\hline
\end{tabular}

Sem requerer grande atenção, nos sete dias analisados, saltam aos olhos a predominância de temas das categorias Comportamento / Moral (sete entre as 14 mais comentadas da semana) e Política / Nacional (cinco no mesmo período). Apenas na sexta-feira (6/10) e no sábado (7/10) é que elas não figuram como a postagem mais comentada, dando lugar ao post da categoria de Entretenimento / Showbiz, que, pelo sucesso do primeiro dia, foi repetida, totalizando, nos dois dias, mais de 11 mil comentários. Comportamento / Moral e Política / Nacional também apresentam bastante incidência entre os posts com nível intermediário em número de comentários.

No caso de O Estado de São Paulo, a disposição ficou da seguinte forma:

\footnotetext{
${ }^{6}$ Disponível em: https://www.facebook.com/folhadesp/posts/2043633029012023. Acesso em: 15 set. 2018.

${ }^{7}$ Disponível em: https://www.facebook.com/folhadesp/posts/2045312485510744. Acesso em: 15 set. 2018.

${ }^{8}$ Disponível em: https://www.facebook.com/folhadesp/posts/2047394018635924. Acesso em: 15 set. 2018.

${ }_{9}^{9}$ Disponível em: https://www.facebook.com/folhadesp/posts/2048308618544464. Acesso em: 15 set. 2018.

${ }^{10}$ Disponível em: https://www.facebook.com/folhadesp/posts/2051583438216982. Acesso em: 15 set. 2018.

${ }^{11}$ Disponível em: https://www.facebook.com/folhadesp/posts/2052749844767008. Acesso em: 15 set. 2018.

12 Disponível em: https://www.facebook.com/folhadesp/posts/2053579114684081. Acesso em: 15 set. 2018.

${ }_{13}$ Disponível em: https://www.facebook.com/folhadesp/posts/2044527215589271. Acesso em: 15 set. 2018.

${ }^{14}$ Disponível em: https://www.facebook.com/folhadesp/posts/2046123648762961. Acesso em: 15 set. 2018.

${ }^{15}$ Disponível em: https://www.facebook.com/folhadesp/posts/2047499095292083. Acesso em: 15 set. 2018.

${ }^{16}$ Disponível em: https://www.facebook.com/folhadesp/posts/2048849411823718. Acesso em: 15 set. 2018.

${ }^{17}$ Disponível em: https://www.facebook.com/folhadesp/posts/2049934731715186. Acesso em: 15 set. 2018.

18 Disponível em: https://www.facebook.com/folhadesp/posts/2051678984874094. Acesso em: 15 set. 2018.

${ }^{19}$ Disponível em: https://www.facebook.com/folhadesp/posts/2053846294657363. Acesso em: 15 set. 2018.
} 
Tabela 2: Posts do Estadão mais comentados por dia, por categoria

\begin{tabular}{|c|c|c|c|c|c|c|c|}
\hline & $\begin{array}{l}20 / 08 / 18 \\
2^{a} \text { feira }\end{array}$ & $\begin{array}{l}\text { 21/08/18 } \\
\text { 3a feira }\end{array}$ & $\begin{array}{l}\text { 22/08/18 } \\
\text { 4a feira }\end{array}$ & $\begin{array}{l}23 / 08 / 18 \\
5 \text { a feira }\end{array}$ & $\begin{array}{l}\text { 24/08/18 } \\
\text { 6a feira }\end{array}$ & $\begin{array}{l}\text { 25/08/18 } \\
\text { sábado }\end{array}$ & $\begin{array}{l}26 / 08 / 18 \\
\text { domingo }\end{array}$ \\
\hline $\begin{array}{l}\text { 1a postagem } \\
\text { mais } \\
\text { comentada }\end{array}$ & $\begin{array}{l}\text { Política/ } \\
\text { Nacional }^{20}\end{array}$ & $\begin{array}{l}\text { Política/ } \\
\text { Nacional }\end{array}$ & $\begin{array}{l}\text { Comport/ } \\
\text { Moral }^{22}\end{array}$ & $\begin{array}{l}\text { Política/ } \\
\text { Nacional }^{23}\end{array}$ & $\begin{array}{l}\text { Política/ } \\
\text { Nacional }^{24}\end{array}$ & $\begin{array}{l}\text { Política/ } \\
\text { Nacional }^{25}\end{array}$ & $\begin{array}{l}\text { Política/ } \\
\text { Nacional }^{26}\end{array}$ \\
\hline $\begin{array}{l}2 \text { a postagem } \\
\text { mais } \\
\text { comentada }\end{array}$ & $\begin{array}{l}\text { Comport./ } \\
\text { Moral }^{27}\end{array}$ & $\begin{array}{l}\text { Política/ } \\
\text { Nacional }^{28}\end{array}$ & $\begin{array}{l}\text { Política/ } \\
\text { Nacional }^{29}\end{array}$ & $\begin{array}{l}\text { Política/ } \\
\text { Nacional }^{30}\end{array}$ & $\begin{array}{l}\text { Política/ } \\
\text { Nacional }^{31}\end{array}$ & $\begin{array}{l}\text { Política/ } \\
\text { Nacional }^{32}\end{array}$ & $\begin{array}{l}\text { Política/ } \\
\text { Nacional }^{33}\end{array}$ \\
\hline
\end{tabular}

Conforme a Tabela 2, a análise da semana por categorias apresenta uma aparente divergência em relação àquela da Folha de São Paulo. Visualmente, destaca-se uma predominância de Política / Nacional em detrimento de Comportamento / Moral. A explicação fácil seria a proximidade das eleições de 2018, fazendo que a temática política ganhasse espaço sobre as questões comportamentais. Embora seja em parte verdade, não explica totalmente o resultado. Assim como na Folha, também no Estadão há uma profunda inter-relação entre as duas categorias, ou seja, há conteúdos estritamente ligados a aspectos morais dentro do noticiário político, e vice-versa, ainda que em menor escala. São matérias que abordavam questões comportamentais ligadas ao então candidato Jair Bolsonaro, como a grande rejeição entre as mulheres, ou um vídeo em que ele pergunta a uma criança se ela sabe atirar.

A análise dos comentários propiciou, por sua vez, a criação de quatro categorias que correspondem a uma etapa de codificação axial: o Refratário Opositivo manifesta claramente a divergência em relação ao tema da postagem, de forma expressa e com recursos verbais de indignação; o refratário irônico denota sua

\footnotetext{
${ }^{20}$ Disponível em: https://www.facebook.com/estadao/posts/2722500604431651. Acesso em: 5 set. 2018.

${ }^{21}$ Disponível em: https://www.facebook.com/estadao/posts/2723276837687361. Acesso em: 5 set. 2018.

${ }^{22}$ Disponível em: https://www.facebook.com/estadao/posts/2727033943978317. Acesso em: 5 set. 2018.

${ }^{23}$ Disponível em: https://www.facebook.com/estadao/videos/266582660636280. Acesso em: 6 set. 2018.

${ }^{24}$ Disponível em: https://www.facebook.com/estadao/posts/2730730766941968. Acesso em: 6 set. 2018.

${ }^{25}$ Disponível em: https://www.facebook.com/estadao/posts/2733852433296468 Acesso em: 6 set. 2018.

${ }^{26}$ Disponível em: https://www.facebook.com/estadao/posts/2735541436460901. Acesso em: 7 set. 2018.

27 Disponível em: https://www.facebook.com/estadao/posts/2722192044462507. Acesso em: 7 set. 2018.

${ }^{28}$ Disponível em: https://www.facebook.com/estadao/posts/2723344607680584. Acesso em: 7 set. 2018.

${ }^{29}$ Disponível em: https://www.facebook.com/estadao/posts/2725196620828716. Acesso em: 7 set. 2018.

${ }^{30}$ Disponível em: https://www.facebook.com/estadao/posts/2728624077152637. Acesso em: 7 set. 2018.

${ }^{31}$ Disponível em: https://www.facebook.com/estadao/posts/2731754756839569. Acesso em: 7 set. 2018.

32 Disponível em: https://www.facebook.com/estadao/posts/2733055186709526. Acesso em: 7 set. 2018.

${ }^{33}$ Disponível em: https://www.facebook.com/estadao/posts/2735027119845666. Acesso em: 7 set. 2018.
} 
discordância por meio de uma subversão linguística, zombando de algum ponto específico do texto ou fazendo referência, em tom jocoso, a alguma outra opinião anteriormente expressa; Refratário Casual é aquele que, mesmo sem a pretensão de gerar polêmica, acaba se diferenciando dos demais usuários e se torna distinto em relação à opinião dos demais no grupo - é o de ocorrência mais rara. Por fim, o comentário Concordante recebe essa classificação pelo seu alinhamento com o tom de significação preponderante no texto da postagem do veículo, o que em alguns casos representa uma postura crítica em relação a determinados temas se a matéria assim apresenta a mesma inclinação. O enquadramento de cada comentário foi feito a partir da experiência adquirida pelo pesquisador na leitura dos mesmos. A constância das manifestações mais frequentes, de certa forma, corrobora a delimitação dessa tipologia.

O termo refratário não é apenas uma escolha aleatória. Trata-se de uma alusão à definição criada por Bernard Rieder (2012) refraction chamber (câmara de refração), em oposição às echo chambers (câmaras de eco) propostas por Sunstein (2001). Para o autor, com quem se concorda neste texto, a terminologia mais apropriada seria a refração pelo fato de as redes sociais privilegiarem a difusão de polêmicas e controvérsias em detrimento a temas estáveis de acordo coletivo.

A refração seria, assim, uma demonstração de força dos usuários frente ao que lhes é imposto, dado o poder de perverter as mensagens originais, seja pela oposição sistemática, seja pela ironia, exatamente como na amostragem aqui elencada no capítulo anterior. Esse parâmetro abala a crença difundida de que as esferas virtuais são meras bolhas ou câmeras de eco e rediscute a difusão da informação em rede. "Ao invés de simplesmente estarem expostos a pessoas com mentalidade semelhante, deve-se considerar que os usuários são a força motriz por trás da produção de valores e entendimentos compartilhados" (RIEDER, 2012, p. 14, tradução minha) $)^{34}$. Parte-se, então, para a análise dos comentários.

Tabela 3: Tipologia dos comentários por dia, nas postagens da Folha

\begin{tabular}{|c|c|c|c|c|c|c|c|}
\hline & $\begin{array}{l}4 / 10 / 17 \\
4 \text { a feira }\end{array}$ & $\begin{array}{l}\text { 5/10/17 } \\
\text { 5a feira }\end{array}$ & $\begin{array}{l}\text { 6/10/17 } \\
\text { 6a-feira }\end{array}$ & $\begin{array}{l}\text { 7/10/17 } \\
\text { Sábado }\end{array}$ & $\begin{array}{l}\text { 8/10/17 } \\
\text { Domingo }\end{array}$ & $\begin{array}{l}\text { 9/10/17 } \\
\text { 2a feira }\end{array}$ & $\begin{array}{l}\text { 10/10/17 } \\
\text { 3a feira }\end{array}$ \\
\hline $\begin{array}{l}\text { Primeiro } \\
\text { coment. em } \\
\text { no de } \\
\text { respostas }\end{array}$ & Concordante & $\begin{array}{l}\text { Refratário } \\
\text { opositivo }\end{array}$ & Concordante & Concordante & $\begin{array}{l}\text { Refratári } \\
\text { o } \\
\text { opositivo }\end{array}$ & $\begin{array}{l}\text { Refratário } \\
\text { opositivo }\end{array}$ & $\begin{array}{l}\text { Refratário } \\
\text { irônico }\end{array}$ \\
\hline
\end{tabular}

\footnotetext{
34 "Instead of merely being exposed to like-mindedness, we consider that the users are the driving force behind the production of shared values and understandings"
} 


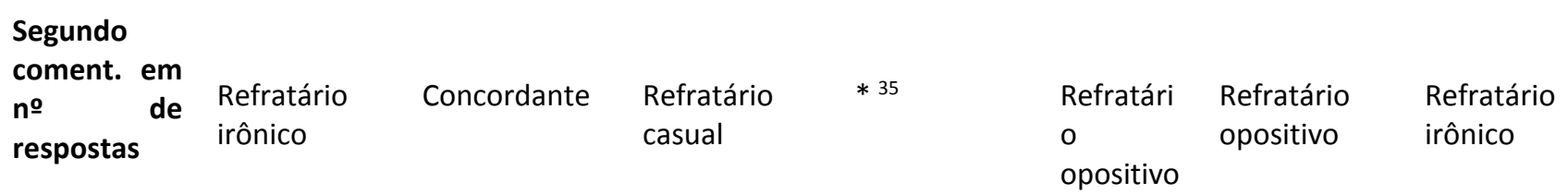

Tabela 4: Tipos de comentários com maior número de respostas nas postagens mais comentadas do Estadão, por dia

\begin{tabular}{|c|c|c|c|c|c|c|c|}
\hline & $\begin{array}{l}20 / 08 / 18 \\
2 \text { a feira }\end{array}$ & $\begin{array}{l}\text { 21/08/18 } \\
\text { 3a feira }\end{array}$ & $\begin{array}{l}\text { 22/08/18 } \\
\text { 4a feira }\end{array}$ & $\begin{array}{l}\text { 23/08/18 } \\
\text { 5a feira }\end{array}$ & $\begin{array}{l}\text { 24/08/18 } \\
\text { 6a feira }\end{array}$ & $\begin{array}{l}\text { 25/08/18 } \\
\text { Sábado }\end{array}$ & $\begin{array}{l}26 / 08 / 18 \\
\text { domingo }\end{array}$ \\
\hline $\begin{array}{l}\text { Primeiro } \\
\text { comentário } \\
\text { em número } \\
\text { de respostas }\end{array}$ & $\begin{array}{l}\text { Refratário } \\
\text { Opositivo }\end{array}$ & Concordante & $\begin{array}{l}\text { Refratário } \\
\text { Irônico }\end{array}$ & $\begin{array}{l}\text { Refratário } \\
\text { opositivo }\end{array}$ & $\begin{array}{l}\text { Refratário } \\
\text { Irônico }\end{array}$ & $\begin{array}{l}\text { Refratário } \\
\text { opositivo }\end{array}$ & $\begin{array}{l}\text { Concordan } \\
\text { te }\end{array}$ \\
\hline $\begin{array}{l}\text { Segundo } \\
\text { comentário } \\
\text { em número } \\
\text { de respostas }\end{array}$ & $\begin{array}{l}\text { Refratário } \\
\text { Irônico }\end{array}$ & $\begin{array}{l}\text { Refratário } \\
\text { opositivo }\end{array}$ & $\begin{array}{l}\text { Refratário } \\
\text { Opositivo }\end{array}$ & $\begin{array}{l}\text { Refratário } \\
\text { opositivo }\end{array}$ & $\begin{array}{l}\text { Refratário } \\
\text { Opositivo }\end{array}$ & $\begin{array}{l}\text { Refratário } \\
\text { opositivo }\end{array}$ & $\begin{array}{l}\text { Concordan } \\
\text { te }\end{array}$ \\
\hline
\end{tabular}

Note-se que, na maior parte das postagens, o comentário principal é refratário ao tom preponderante nos textos dos jornais. Entre os comentários concordantes, praticamente não há oposição por parte dos usuários responsivos, formando blocos com relativa unidade. Nas manifestações refratárias, a polêmica surge em todos os comentários. Em apenas um dos dias observados, os dois principais comentários foram concordantes.

Entre os principais tipos de comentário, percebe-se a preponderância do Refratário opositivo (13 manifestações em 13), seguido pelo Concordante (7), Refratário irônico (6) e Refratário casual (1). A categoria Entretenimento / Showbiz, representada pela mesma postagem repetida dois dias seguidos, teve como principal comentário, em ambas datas, expressões concordantes. De modo geral, apresentou pouca polêmica.

A análise permite algumas considerações a partir dos dados aqui expostos. As categorias de Política / Nacional e Comportamento / Moral, além de liderarem o número de comentários entre as postagens nas duas semanas analisadas, acabam fundindo-se mutuamente. Essa mescla fica clara quando identificamos que há comentários sobre política em textos sobre Comportamento / Moral e vice-versa, em uma fusão

\footnotetext{
${ }^{35}$ Nesta data, não houve segunda postagem que mobilizasse as atenções dos usuários; o número de respostas a comentários fica pulverizado, nunca ultrapassando três.
} 
temática. Tal perspectiva, de união entre política e moral, é um mote bem explorado pelo então candidato à presidência da República Jair Bolsonaro, casualmente protagonista das principais postagens de política naquelas semanas analisadas.

Nas próximas páginas, pretende-se explicar, por meio de uma perspectiva fenomenológica da Sociologia do Conhecimento, como essas duas instâncias - as categorias das postagens dos veículos e a tipologia dos comentários - são interligadas. Essa junção de dessas duas dimensões, correspondente à terceira fase de codificação da Teoria Fundamentada, busca traçar uma linha teórica para o entendimento do objeto em questão, da expressão por meio de comentários em suporte on-line.

\section{Fatores coercitivos para comentários refratários}

A assunção de política e moral como temas cruciais é reveladora de um desejo por uma reflexão profunda e estrutural sobre os rumos a serem tomados por uma sociedade, dado que ambas as temáticas envolvem perspectivas mais amplas sobre visões de mundo em qualquer discussão. Cabe destacar, preliminarmente, que essa é uma expressão comum ao longo da história, de recrudescimento moral como resposta a abalos sociais maiores. Foi assim, por exemplo, na Alemanha após a I Guerra Mundial e também nos Estados Unidos na década de 1950, após a II Guerra (WAINBERG, 1995). Transcorrido um período de relativa estabilidade política e econômica, iniciada em 1995, o Brasil para em junho de 2013, com expressivas manifestações de rua, e digladia-se em ódio na eleição de 2014, cujos desdobramentos são sentidos até hoje. Em um curto período, menos de três anos depois, o país convive com a possibilidade de uma nova mudança presidencial. É, assim, um cenário bastante propício para o surgimento dos posicionamentos observados.

Sob o ponto de vista da tipologia de comentários, fica claro que um tipo parece sempre presente, pronto a ser destacado pelo algoritmo que os ordena: o refratário. Tais manifestações, com pequenas variações, foram comuns em todas as postagens, inclusive na categoria de Entretenimento / Showbiz. A saliência dessa tipologia remete a uma indagação: Será possível elaborar uma trajetória fenomenológica para a formulação de comentários? A Sociologia do Conhecimento parece oferecer elementos para uma resposta, que se inicia pelo próprio entendimento da linguagem, como observam Müller e Petrik (2016):

Um enunciado é um projeto. A habilidade natural da fala do ser humano depende de um código estruturado, a linguagem, para que se realize plenamente. $O$ ato de fala é composto, portanto, de início, por uma relação 
dialética entre uma capacidade biológica e a linguagem normatizada. Tal exemplo indica que há, no ser humano, uma proclividade à criação de referenciais ou uma tendência a orientar-se com e por intermédio deles. (MÜLLER, PETRIK, 2016, p. 113)

Peter Berger e Thomas Luckmann (2013), ao abordarem o processo de construção social da realidade e ampliarem as acepções de Schütz, enfatizam a necessidade do indivíduo de orientação por referências próximas, sendo os sistemas que lhe servem de base em si dotados de capacidade para formular hierarquias de prioridades. Além da linguagem, e até antes dela, inclui-se aí a própria consciência, como delimitação de percepção e de um campo para se agir. "A consciência é sempre intencional. Sempre 'tende para' ou é dirigida para objetos. Nunca podemos apreender um suposto substrato da consciência enquanto tal, mas somente a consciência de tal ou qual coisa" (BERGER, LUCKMANN, 2013, p. 37). A consciência teria, portanto, em sua essência, um viés de determinação por si própria, independente da coação de agentes externos como estruturas de poder ou de persuasão ideológica, ainda que tais fatores estejam permanentemente presentes ou ainda que historicamente, no Ocidente, tenham ajudado a moldar essa orientação.

O uso de uma tendência de pensamento é a solução natural para a sobrevivência cotidiana. A criação de categorias nas quais enquadramos situações, personagens, vivências e conhecimentos diversos Alfred Schütz chamou de "tipificação". Seria a salvaguarda a que recorremos para dar um contorno de proximidade ao novo, ao estranho e, até mesmo, ao que se opõe a nós. A tipificação, para formular-se, é um gatilho que se aciona a partir de um "estoque de conhecimento".

O estoque de conhecimento da vida mundana está relacionado de diversas formas com a situação experienciada pelo sujeito. É construído pelas sedimentações das experiências anteriores, ligadas a situações. Inversamente, cada experiência presente é inserida no fluxo das vivências e em uma biografia, de acordo com os diferentes tipos e relevâncias encontrados no estoque de conhecimento. (SCHÜTZ, LUCKMANN, 1973, p. $99-100)^{36}$

Um estoque de conhecimento, por mais cristalizado que esteja, é constantemente sujeito a abalos, e são muitos os fatores a colaborar para isso, além da língua e da própria consciência. Outro elemento talvez seja o espaço. "Em cada situação meu corpo atua como um centro de coordenação no mundo, com um acima e abaixo, direita e esquerda, e atrás e em frente" (SCHÜTZ, LUCKMANN, 1973, p. 102, tradução minha).

\footnotetext{
36 "The lifeworldly stock of knowledge is related in many ways to the situation of the experiencing subject. It is build on sedimentations of formerly actually present experiences that were bound to situations". Pelos termos e noções empregadas ("mundo da vida", "estoque de conhecimento, "experiências", "biografia", "tipos" e "relevâncias"), esse pode ser considerado um parágrafo síntese do pensamento de Schütz, ainda que, a partir daí, muitos sejam os desdobramentos advindos.
} 


\section{ALCEU}

ISSN: 2175-7402

O espaço e, para além dele, o ambiente são, pois, definidores e, mais do que dimensões físicas, predispositores ontológicos. Justamente por isso, torna-se irrelevante falar-se em espaço físico ou virtual.

Associado a esses elementos está o tempo, talvez com maior capacidade de coerção. "Eu vivencio a necessidade do tempo do mundo pela espera e subordinação das minhas ações ao princípio de 'primeiro as primeiras coisas'” (SCHÜTZ, LUCKMANN, 1973, p. 100, tradução minha ${ }^{37}$ ). Ou seja, qualquer ato demanda uma espacialidade para ocorrer e obedece a uma aceleração natural do tempo sobre qualquer projeto anteriormente formulado, calcada na evidência de que prioridades são prioritárias. Essa estrutura permeia todo planejamento de ação, do mais simples, ao se despertar pela manhã, até formulações abstratas, como muitas vezes aquelas compartilhadas nas redes sociais, ainda que estas sejam, em geral, um local mais propício à difusão de conhecimentos e percepções comuns. Berger e Luckmann bem resumem o fator constrangedor do tempo:

A mesma estrutura temporal, como já indicado, é coercitiva. Não posso inverter à vontade as sequências impostas por ela, 'primeiro as primeiras coisas' é um elemento essencial no meu conhecimento da vida cotidiana (...) Também a mesma estrutura temporal fornece a historicidade que determina minha situação no mundo da vida cotidiana. (BERGER, LUCKMANN, 2013, p. 45).

Como dito, tempo, espaço e comunicação andam juntos. No que aqui está em contexto, a socialidade conflitiva em sites de redes sociais, pode-se agregar outro elemento, o algoritmo que dispõe as informações na página pessoal de cada usuário. Como se sabe, tal ordenamento não se dá de forma aleatória. Bem ao contrário, segue lógica própria, nunca evidente ao usuário, mas que se orienta a partir da vontade mercadológica do grupo empresarial que controla a plataforma, sobretudo baseado no transcurso do tempo, tão bem representado pelo termo Timeline, que nomeia uma das seções do Facebook. Como já havia notado Harold Innis, "Um monopólio [da técnica] que acentua a disseminação mais rápida [da informação] causa uma profunda perturbação na sociedade" (INNIS, 2011, p. 282). Passado, presente e futuro ligam-se inextrincavelmente na temporalidade proposta por Schütz, que bem se adapta à explicação para a elaboração de comentários. Ao projetar cada ação (presente voltado ao futuro), avalio como ela se desenrolaria, baseado em experiências passadas e vislumbrando as possibilidades de êxito, numa simulação de ato concluído, como se já houvesse sido finalizada ("se fizesse isso, resultaria naquilo"). Como descreve Schütz, se me proponho a escrever uma carta,

37 "I experience the necessity of world time in waiting and in subordination of my actions to the principle of 'first things first' " 
Eu não posso simplesmente imaginar uma carta. Eu tenho a escolha de apenas poucas possibilidades, que conheço através da minha experiência prévia: caneta, lápis, máquina de escrever, cada uma tem em conta um horizonte de significação, que já foi anteriormente explicado (SCHÜTZ, LUCKMANN, 1973, p. 20, tradução minha) $)^{38}$

A questão do tempo em Schütz enfatiza a multiplicidade de momentos na contemporaneidade. Se as relações sociais se tornam cada vez mais complexas, só é possível entendê-las em plenitude pela dinâmica envolvida em temporalidades diversas que, cada vez mais, andam juntas, sendo impossível dissociá-las, ainda que salte aos olhos a busca irrefreável por se viver o momento presente, o aqui e agora. E é essa a tônica cada vez mais presente na sincronia entre comentários e respostas on-line.

O próprio hábito de escrever sobre assuntos públicos em redes sociais de suporte digital tem um pouco do seu fascínio explicado por esse movimento catártico, baseado no presenteísmo, em que se expressa um anseio de futuro, rememorando - intencionalmente ou não - o que já se viveu e experimentou e que, portanto, no âmbito afetivo, nos é próximo. Não há, então, por essa perspectiva, predomínio de uma determinada temporalidade ou mesmo a predeterminação a partir de um arcabouço de experiências estocadas. "Em resumo, por meio da atitude natural eu não ajo somente através de uma hierarquia de planos biograficamente determinados. Mais do que isso, eu vejo consequências típicas de meus atos que são apreendidas como típicas" (SCHÜTZ, LUCKMANN, 1973; p. 20, tradução minha) ${ }^{39}$. Ou seja, previam os autores que há uma naturalização na adoção de determinados planos de ações cotidianas, e essa é uma concepção bastante válida para os comentários. Como ato pessoal intersubjetivo, uma postagem em rede social, tanto as de caráter mais privado como as de domínio público, é uma reafirmação de si, com certo prazer envolvido, para a chancela ou o rechaço dos outros, alhures, que comigo estão em contato por meio digital. Assim, passamos das variáveis subjetivas para as sociais.

\section{Conversação, conflito e poder}

Como ponte entre o sujeito e o mundo da vida, a linguagem provavelmente é o código mais amplo de tipificações, com regras comuns que são moldadas a partir das apropriações e dos usos subjetivos. "A

\footnotetext{
38 "I cannot merely imagine a letter. I have the choice of only few possibilities, which I know about through my previous experience: pen, pencil, typewriter, each of which has in turn a horizon of meaning which has already been explicated."

39 "In short, within the natural attitude I do not act only within a biographically determined hierarchy of plans. Rather, I also see typical consequences of my acts which are apprehended as typical".
} 
vida cotidiana é, sobretudo, a vida com a linguagem, e por meio dela, de que participo com meus semelhantes" (BERGER, LUCKMANN, 2013, p. 56).

Mais do que um mero meio, a expressão linguística, como técnica de partilhamento e de apreensão / difusão de conhecimentos e perspectivas pessoais, tem um viés próprio para a sedimentação / alteração do social. "A linguagem objetiva as experiências partilhadas e torna-as acessíveis a todos dentro da comunidade linguística (...) Ainda mais, a linguagem fornece os meios para a objetivação de novas experiências" (BERGER \& LUCKMANN, 2013, p. 93). Essa característica própria da língua é comumente deixada de lado no estudo da Comunicação Social. "A linguagem tem sua origem na situação face a face, mas pode ser facilmente destacada desta" (BERGER, LUCKMANN, 2013, p. 93). Nada mais atual para a situação vivida nas redes sociais em meio virtual.

O recurso linguístico enfatiza crenças, inicialmente aquelas relativas que temos de nós próprios. Na rede social virtual, ainda que os emissores de cada enunciado estejam identificados por seus perfis sociais, impõe-se uma espécie de anonimato pela distância física em que se encontram os personagens. Esse distanciamento é, essencialmente, propositivo de indisposições. Relembrando George Simmel (1983, p. 128), “A antipatia é a fase preliminar do antagonismo concreto que engendra as distâncias e as aversões, sem as quais não poderíamos, em absoluto, realizar a vida urbana". Essa compreensão é fundamental para entendermos, também, a profusão de conflitos que se estabelecem em ambiente digital, tão próxima que é da definição de Schütz (1979) para o "mundo dos contemporâneos", o Mitwelt. Se no distanciamento anônimo das redes tecnológicas preponderasse a harmonia absoluta, tal atividade, a de frequentá-las e manifestar-se por meio delas, seria monótona e meramente conectiva, sem nenhum espaço para debates como os aqui observados.

A introdução de novos elementos, quaisquer que sejam, é em si desestabilizadora de antigas crenças depositadas no estoque de conhecimento pessoal de cada um. Eles obrigam o desencadeamento de uma reflexão, por menor que seja, a fim de que a nova informação seja decodificada. "Na atitude natural, eu só me torno consciente do tom deficiente do meu estoque de conhecimento se uma nova experiência não se 
encaixa no que era até o momento válido dentro do esquema do mundo tomado como dado" (SCHÜTZ, LUCKMANN, 1973, p. 8, tradução minha) $)^{40}$.

Pode-se dizer que, na situação face a face, dado o inusitado das ponderações do outro com quem interagimos, e pela velocidade com que se desenrola, as tipificações exigem maior rapidez e, portanto, tornam-se pouco propícias ao aprofundamento reflexivo. Ainda que conserve muitas características similares às da oralidade, a interação mediada por dispositivos tecnológicos pressupõe a temporalidade atinente ao ordenamento cognitivo da escrita, tão bem relatado por Schütz (1973). Mesmo permeadas pela coloquialidade e pelo despojamento, essas mensagens vêm impregnadas de sentidos mais amplos, que colocam em perspectiva até mesmo os desideratos de cada indivíduo quanto aos destinos do país. Ao contrário do que se pode pensar, o conflito, então, deve ser entendido como fator que agrega ao todo, conforme vislumbrado por Georg Simmel (1983).

As discussões aqui analisadas não parecem indicar que, após a leitura de comentários refratários, possa haver uma mudança considerável de opinião em relação ao posicionamento inicial de cada usuário. Mas muitos geram algum tipo de interpelação suficiente, no mínimo, para demonstrar as deficiências em estoques de conhecimento de outros. Esse caráter híbrido do conflito como sociação, que envolve uma aparente contradição entre repulsa e aproximação, em uma luta que, em última instância, seria por poder, é bem percebido por Jochen Dreher (2011), ao se propor estabelecer uma "fenomenologia do poder", oscilando entre familiaridade e estranheza. Afirma o autor que a definição de poder não é algo dado. Seria menos uma estrutura acabada do que algo que se configura a partir de cada relação. Para Dreher (2011), o poder é sempre relacional, ou seja, se constitui como uma vontade em relação a um outro, é sempre exercido em relação a alguém. Podemos dizer que, de certa forma, obedece a mesma dinâmica da comunicação e, mais ainda, dos sites de redes sociais. A relação entre intento e desejo individual, e a comunicação disso como meio para uma realização coletiva, também é bem explorada pelo autor ao citar Karl Mannheim, segundo quem, nas disputas por poder, os grupos buscam "fazer de sua interpretação de mundo particular a interpretação geral de mundo" (DREHER, p. 475, 2011). De forma genérica, é isso que se

\footnotetext{
40 "I only become aware of the deficient tone of my stock of knowledge if a novel experience does not fit into what has up until now been taken as the taken-for-granted valid reference schema".
} 
constata nas opiniões verbalizadas nos comentários aqui analisados: fazer valer a visão do mundo individual de cada um.

\section{Debates, identidade e socialidade contemporâneas}

Ainda que conflitantes e antagônicos, os comentários diários cotidianos constituem uma mesma totalidade e uma preocupação comum: no caso, o futuro do país. É semelhante ao momento de expansão do rádio e da televisão no Brasil, entre as décadas de 1930 e 1950 do século XX, sobre o qual Jacques Wainberg observa que naquele "novo contexto de redes sofisticadas que se interligam, os brasileiros têm o que partilhar. O objeto do Brasil tornou-se o Brasil" (WAINBERG, 2001, p. 14). Tal inclinação propiciaria, segundo o autor, primeiro uma valorização da cultura nacional e, posteriormente, durante a Ditadura Militar, a elaboração de um projeto nacional soberano calcado na interligação por redes.

A experiência que o país atravessa na atualidade, contudo, é inédita sob o ponto de vista de exposição dos conflitos. Ao escapar da perseguição nazista na Europa conflagrada da Segunda Guerra Mundial e chegar ao Brasil, o escritor austríaco Stefan Zweig assim descreveu o país que o acolheu em seus últimos dias de vida:

Algo de inverossímil e de benfazejo envolve aquele que acabou de fugir da absurda loucura da Europa: a total ausência de qualquer hostilidade na vida pública e na privada. (...) Todas as contradições, mesmo no campo social, são significativamente menos acentuadas (ZWEIG, 2008, p. 20).

Guardadas as proporções, a introdução de novas tecnologias, antes pelo rádio e pela TV, e agora em suporte virtual, compartilham um impulso do público / usuários no sentido de discutir aspectos fulcrais da sociedade, começando pela política e aguçando-se com temas morais / identitários e, de certa forma, negando aquela impressão colhida por Zweig. "De nossa identidade falamos sempre que dizemos quem somos e quem queríamos ser. E neste conceito que elaboramos a respeito de nós mesmos se entretecem elementos descritivos e valorativos", vaticinava Jürgen Habermas (1989, p. 115). Ou seja, a cada fala em site de rede social narcisicamente orientada, fala-se de si próprio e da visão do mundo que gostaríamos ver realizada.

Num sistema de relevâncias como é aquele disposto com o auxílio de algoritmos, o refratário sobressai. Mais do que isso, convoca um cidadão comum ao embate cívico pelos destinos do país. No Brasil, de uma forma rudimentar, pode-se dizer que a oposição e a crítica, que exigem certa maturidade 
democrática, não são bem recebidas como agregadoras. Mais comum talvez seja a competição de grupos em torno do controle do Estado e do poder daí advindo, sejam oligarquias, grupos econômicos oligopolistas, classe política ou mesmo, em menor escala, corporações de servidores públicos. Na ausência de meios tradicionais de expressão democrática, as redes sociais agora assumem uma nova função para as manifestações coletivas enunciativas de projetos. ${ }^{41}$

Ao diferenciar o laço social da modernidade e o da contemporaneidade, Juremir Machado da Silva (2012) explica a transposição e, em parte, seu fascínio sedutor:

Na abstração racional, o contraditório deve ser expurgado. No concreto das práticas cotidianas, o paradoxo alimenta os imaginários. Em cada personagem, convivem o sim e o não, o bem e o mal, a verdade e a ilusão, a ideologia e a cultura, a compreensão e a explicação, o afeto e a desrazão. Tudo isso necessita ser compreendido em situações sociais de colaboração e de conflito. (SILVA, 2012, p. 21)

As redes sociais são, portanto, as tecnologias em que se irrigam os imaginários movidos a paradoxos e conflitos como elementos colaborativos que são. Oferecem, enfim, a potencialidade necessária para que se abalem os estoques de conhecimento individuais, diluindo-se nas teias do coletivo. Premências de incontinências (verbais) que (res)significam o ordinário do cotidiano socialmente (compartilhado).

\section{Considerações}

O extrato aqui analisado remete a algumas considerações. A democracia especializou-se em ponderar equilíbrios entre visões de mundo opostas. Quando se passa a discutir comportamentos, deslocase o debate público para outro plano, como um sucedâneo deliberativo que, a pretexto de discutir modos de vida e valores morais que os cercam, afastam-se do foco as resoluções político-administrativas que afetam diretamente a população. Michel Maffesoli bem sintetiza esse deslocamento. “A transfiguração do político completa-se quando a ambiência emocional toma o lugar da argumentação ou quando o sentimento substitui a convicção" (MAFFESOLI, 2005, p. 115).

Na maior parte das postagens de política coletadas, falava-se de Jair Bolsonaro, e, em conjunto com ele, vinha embutida uma discussão comportamental. As redes já repercutiam a fusão de refração com política e moral, o que, de certo modo, estava consubstanciado na figura de Bolsonaro há décadas. Para fins político-eleitorais, pode-se entender como uma apropriação do emocional que invariavelmente se

\footnotetext{
${ }^{41} \mathrm{Em}$ 1941, Stefan Zweig notava que "Para o Brasil que passou trezentos anos dependente e tutelado, os direitos parlamentares e a liberdade de imprensa são coisas muito novas, que deixam todos inebriados" (ZWEIG, 2008, p. 71).
} 


\section{ALCEU}

ISSN: $2175-7402$

desencadeia quando os temas em questão envolvem dilemas sobre a contemporaneidade. Deslocamento discursivo com anuência do público, rebelado contra algo que ainda merece estudo mais profundo. Politicamente, pode ser considerada uma "atitude fundamentalista", na definição de Peter Berger e Thomas Luckmann, que pretende "reconquistar a sociedade toda para valores e tradições antigos. Os políticos tentaram sempre de novo explorar para seus objetivos emoções ligadas a essa atitude" (BERGER; LUCKMANN, 2004, p.79).

Uma perspectiva baseada na Sociologia do Conhecimento nos levou a resultados que, de certa forma, se assemelham e são corroborados pelas urnas, tendência perceptível já desde a primeira coleta na Folha, como se o desenrolar dos fatos político-eleitorais viesse confirmar o que estava contido nos comentários das redes. Substratos pouco abstratos de extravasamentos da "realidade", de cada um e de todos, e prontos a se expressarem no mundo virtual. Virtus como potência que se cristaliza, nos casos aqui expostos, pela refração.

Manuel Luís Petrik

ORCID: https://orcid.org/0000-0002-7704-1818 PUC-RS, Departamento de Comunicação Social, Porto Alegre (RS), Brasil. Doutor em Comunicação Social pela PUC-RS E-mail: petrikpereira@yahoo.com

Recebido em: 5 de maio de 2020.

Aprovado em: 26 de julho de 2020.

\section{Referências:}

BAUDRILLARD, Jean. A transparência do mal: ensaio sobre os fenômenos extremos. Campinas: Papirus, 1990.

BERGER, Peter; LUCKMANN, Thomas. A Construção Social da Realidade - Tratado de sociologia do conhecimento. Petrópolis: Vozes, 2013.

. Modernidade, Pluralismo e Crise de Sentido: a orientação do homem moderno. Petrópolis: Vozes, 2004. 
CHARMAZ, Kathy. A Construção da Teoria Fundamentada: guia prático para análise qualitativa. Porto Alegre: Artmed, 2009.

DREHER, Jochen. Fenomenologia do Poder. Civitas, Porto Alegre, v. 11, n. 3. p. 479-490, set-dez de 2011.

FRAGOSO, Suely; RECUERO, Raquel; AMARAL, Adriana. Métodos de pesquisa para internet. Porto Alegre: Sulina, 2015.

GLASER, Barney G.; STRAUSS, Anselm L.. The discovery of grounded theory: strategies of qualitative research. New Jersey: Aldine Transaction, 2006.

HABERMAS, Jürgen. Identidades nacionales y postnacionales. Madri: Editorial Tecnos, 1989.

INNIS, Harold. O viés da comunicação. Petrópolis: Vozes, 2011.

MAFFESOLI, Michel. A Transfiguração do Político: a tribalização do mundo. Porto Alegre: Sulina, 2005.

MÜLLER, Angelo; PETRIK, Manuel. Normatização, grupo e ódio: dinâmica de comentários em redes sociais. Novos Olhares, São Paulo, v. 5, n. 2, p. 112-122, dez. 2016.

RIEDER, Bernhard. The refraction chamber: Twitter as sphere and network. First Monday, Vol. 17, n. 11, nov. 2012.

ROSENTHAL, Gabriele. Pesquisa social interpretativa: uma introdução. Porto Alegre: Edipucrs, 2014.

SCHÜTZ, Alfred. Fenomenologia e relações sociais. Rio de Janeiro: Zahar Editores, 1979.

; LUCKMANN, Thomas. The structures of life-world. Evanston: Northwestern University Press, 1973.

SILVA, Juremir Machado da. As tecnologias do imaginário. Porto Alegre: Sulina, 2012.

SIMMEL, Georg. A Natureza Sociológica do Conflito. In: MORAES FILHO, Evaristo de. Simmel. São Paulo: Ática, 1908/ 1983, 122-134.

SUNSTEIN, Cass. Echo chambers: Bush v. Gore, impeachment and beyond. New Jersey: Princeton University Press, 2001.

WAINBERG, Jacques A.. Casa grande e senzala com antena parabólica: telecomunicação e o Brasil. Porto Alegre: Edipucrs, 2001.

; A nova imprensa na nova/ velha Alemanha. Intercom - Revista Brasileira de Ciências da Comunicação, São Paulo, v. XVIII, no 1, p. 50-66, jan/jun 1995.

ZWEIG, Stefan. Brasil, um país do futuro. Porto Alegre: L\&PM, 2008. 


\section{Resumo}

$\mathrm{O}$ artigo traz resultados parciais de tese de doutorado, que contempla a polêmica em comentários de usuários em perfis de jornais brasileiros no Facebook. São analisadas duas semanas de postagens nas páginas da Folha de São Paulo e de O Estado de São Paulo na referida rede social. A base metodológica adotada é a Teoria Fundamentada (GLASER, STRAUSS, 2006). Foram criadas categorias temáticas para as postagens, além de ter sido formulada uma tipologia de comentários. Como resultados mais salientes aparece o grande interesse dos leitores por temas políticos, sucedido por assuntos morais e comportamentais, ao mesmo tempo que, em termos de manifestação dos usuários das redes, destaca-se o tom refratário dos comentários. A junção dessas temáticas com esse modo de expressão do público compõe a reflexão final do texto.

Palavras-chave: Polêmica. Conflito. Comentários on-line. Facebook. Redes sociais.

\section{Abstract}

The article presents partial results of a doctoral thesis, which contemplates the controversy in user comments on profiles of Brazilian newspapers on Facebook. Two weeks of posts are analyzed on the pages of Folha de São Paulo and O Estado de São Paulo on that social network. The methodological approach adopted is the Grounded Theory (GLASER, STRAUSS, 2006). Thematic categories for posts were created, in addition to a typology of comments. As relevant results, it could be highlighted readers' great interest in political themes, followed by moral and behavioral issues, while, in terms of the manifestation of network users, the refractory tone of the comments stands out. The combination of these themes with this mode of public expression addresses the final reflection of the text.

Keywords: Polemics. Conflict. On-line comments. Facebook. Social media. 


\section{Resumen}

El artículo trae resultados parciales de una tesis doctoral, que contempla la controversia en los comentarios de los usuarios en perfiles de los periódicos brasileños en Facebook. Se analizan dos semanas de publicaciones en las páginas de Folha de São Paulo y O Estado de São Paulo em esa red social. La base metodológica adoptada es la Teoría Fundamentada (GLASER, STRAUSS, 2006). Se crearon categorías temáticas para las publicaciones y una tipología de comentarios. Como resultados más relevantes, aparece el gran interés de los lectores en los temas políticos, seguido de cuestiones morales y de comportamiento, mientras que, en términos de la manifestación de los usuarios de la red, se destaca el tono refractario de los comentarios. La combinación de estos temas con este modo de expresión pública constituye el reflejo final del texto

Palabras clave: Controversias. Conflicto. Comentarios en línea. Facebook. Redes sociales.

Este artigo é publicado em acesso aberto (Open Access) sob a licença Creative Commons Attribution Non-Commercial (CC-BY-NC 4.0), que permite que outros remixem, adaptem e criem a partir do seu trabalho para fins não comerciais, e embora os novos trabalhos tenham de lhe atribuir o devido crédito e não possam ser usados para fins comerciais, os usuários não têm de licenciar esses trabalhos derivados sob os mesmos termos. 